\title{
Protéines à activités biologiques : lactoferrine et lactoperoxydase. Connaissances récemment acquises et technologies d'obtention
}

\author{
JP Perraudin
}

\author{
Biopole, 75, Bd Edmond Machtens b16, B-1080 Bruxelles, Belgique
}

\begin{abstract}
Résumé - Depuis fort longtemps, les hommes ont su mettre à profit les propriétés fonctionnelles et nutritionnelles des protéines laitières. La connaissance de ces propriétés permet aujourd'hui d'utiliser ces protéines en tant que matières premières de base indispensable dans la technologie de nouveaux produits.

À l'heure actuelle, avec des techniques de séparation de plus en plus sophistiquées, de nouvelles voies d'utilisation ont pu être explorées puis exploitées. Elles représentent les premières utilisations non alimentaires sur lesquelles est venue se greffer une approche de recherche totalement différente de celle pratiquée jusqu'à nos jours dans le secteur laitier.

En effet, l'amélioration des techniques de purification a permis à un certain nombre d'entreprises de disposer actuellement de quelques protéines laitières en quantités suffisantes afin d'envisager l'investigation de nouveaux horizons à plus hautes valeurs ajoutées.

C'est actuellement le cas de la lactoferrine et de la lactoperoxydase.

Ces 2 molécules, présentes dans tous les liquides de sécrétion chez l'homme, ont, si l'on en juge le nombre de publications, suscité un grand intérêt auprès des scientifiques de recherche fondamentale. Depuis de nombreuses années, les chercheurs se penchent sur l'étude des propriétés spécifiques de la lactoferrine et de la lactoperoxydase et essaient de comprendre leur rôle physiologique. II est vrai qu'en tant que piégeur du fer, la lactoferrine avait surtout suscité des recherches sur son rôle antibactérien; mais à l'heure actuelle, d'autres activités de la protéine sont mises en évidence démontrant son effet sur la croissance cellulaire, son rôle comme transporteur du fer et son action immunostimulatrice.

En ce qui concerne la lactoperoxydase, les recherches sont principalement axées sur son activité antibactérienne, mais depuis quelque temps, on a pu démontrer une action spectaculaire de l'enzyme contre certains virus.
\end{abstract}

lactoferrine / lactoperoxydase / technique de purification / activité biologique

Summary - Biologically-active proteins. Recently-acquired knowledge and separation technology. Mankind has been exploiting the functional and nutritional properties of milk proteins for centuries. Knowledge of these properties now enables us to use them as indispensable raw materials for new-product technology. At the present time, thanks to increasingly more sophisticated separation techniques, new avenues for their use have been explored and adopted. These are the first non-food uses of these proteins. They have been developed using a totally different research approach from that used until now in the dairy industry.

Improved purification techniques have enabled a certain number of enterprises to obtain sufficiently large quantities of milk proteins to make the investigation of new, higher-added-value horizons worthwhile. This is the case for lactoferrin and lactoperoxidase. Judging by the number of articles in the literature, these two molecules, which are found in all of the secretions of the human body, have attracted great interest in fundamental research. Researchers have been studying the specific prop- 
erties of lactoferrin and lactoperoxidase and to have tried to understand their physiological roles for many years. Given lactoferrin's ability to trap iron, research focused primarily on lactoferrin's antibacterial effect. Today, however, the protein's other properties - its effect on cell growth and its role in iron transport, have been discovered. Lactoperoxidase research has likewise focused mainly on the enzyme's antibacterial activity. However, lactoperoxidase has recently been shown to display spectacular action against some viruses.

lactoferrin / lactoperoxidase / purification process / biological activity

\section{MÉTHODES D'OBTENTION \\ DE LA LACTOFERRINE ET DE LA LACTOPEROXYDASE}

À en juger par l'abondance de la littérature scientifique et des brevets, concernant la mise au point de l'extraction de la lactoferrine et de la lactoperoxydase, de nombreux chercheurs se sont penchés sur le sujet. Ces protéines sont de plus en plus recherchées, non seulement pour leur intérêt nutritionnel, mais surtout pour d'autres propriétés qui leur permettent de trouver un débouché de valorisation dans d'autres secteurs tels que la pharmacie et la cosmétique.

La figure 1 montre un schéma classique d'extraction industrielle à partir d'une colonne renfermant une résine échangeuse d'ions. Le système est simple. On fait passer sur cette résine, la matière première (lactosérum, lait) contenant la lactoferrine et la lactoperoxydase. Après absorption, on lave la résine plusieurs fois, puis on fait passer une solution de décrochage qui sera, soit concentrée par ultrafiltration, soit précipitée, pour éliminer les contaminants. Le concentrat ou le surnageant peut, suivant les cas, être rechromatographié, pour séparer la lactoferrine de la lactoperoxydase et obtenir des produits dont le taux de pureté sera supérieur à $90 \%$. Avant de procéder à l'extraction suivante, on devra régénérer la résine.

Ce qui différencie principalement les procédés, c'est le type de résine utilisé pour l'extraction (tableau I). Roussel Uclaf (1985) fait appel, pour n'extraire que la lactoferrine, à des groupements carboxyméthyls greffés sur un support composé de copolymère acrylique. Entremont (1988) utilise une résine dont le support est de la silice, sur lequel se trouvent fixés des groupements sulfopropyls. Par contre, Snow Brand (1988) utilise des polysaccharides tels que la cellulose ou la chitine es-

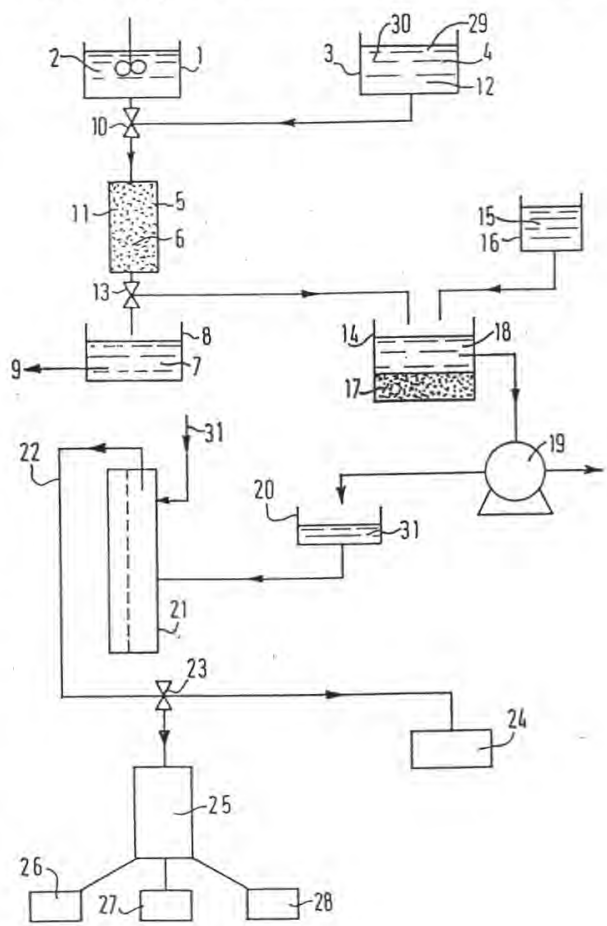

Fig 1. Schéma d'extraction (Entremont, 1988). Extraction method (Entremont, 1988; Patent No (8703517). 
térifiées avec de l'acide sulfurique anhydre; Oléofina (1986), de l'alginate ou du carraghénane polymérisé, soit sous forme de billes, soit sous forme de fils. SMR (1988) dont le procédé a la particulairté d'obtenir en une étape la lactoferrine et la lactoperoxydase, utilise de la Sépharose comme support couplé avec des groupements sulfopropyls. De son côté, Morinaga (1988) a préféré un échangeur d'ions faibles qui possèdent des groupements carboxyméthyls, afin de n'obtenir que la lactoferrine.

Plusieurs points sont primordiaux, en général, lorsque l'on veut extraire de façon industrielle la lactoferrine et la lactopéroxydase.

Tout d'abord, il faut établir le «design» du module qui recevra la résine, afin de ne pas perturber la ligne de traitement habituelle de la matière première.

Ensuite, il faudra étudier les paramètres physiques des résines:

- en tenant compte de la taille des billes pour éviter tout colmatage dans le module; - en tenant compte de la surface interne et externe d'absorption des billes, de façon à contrôler le rapport existant entre la vitesse d'écoulement de la matière première

Tableau I. Méthodes d'extraction utilisées par différentes sociétés.

Extraction methods performed by different companies.

Société Produit Échangeur d'ions pH Lavage solution Décrochage solution

\begin{tabular}{|c|c|c|c|c|c|}
\hline Roussel Uclaf & LF & $\begin{array}{l}\text { CM Trisacryl (IBF) } \\
\text { CM Sepharose CL } 6 \text { B } \\
\text { (pharmacie) }\end{array}$ & $7-8$ & $0,15 \mathrm{~mol} . \mathrm{I}^{-1} \mathrm{NaCl}$ & $0,4 \mathrm{~mol} . \mathrm{l}^{-1} \mathrm{NaCl}$ \\
\hline Oléofina & LF-LP & $\begin{array}{l}\text { Polysaccharide } \\
\text { Acide: } \\
\text { Alginate } \\
\text { Carraghénane }\end{array}$ & 6,5 & $0,03 \mathrm{~mol}^{-1} \mathrm{I}^{-1} \mathrm{CaCl}_{2}$ & 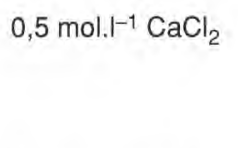 \\
\hline Elf Aquitaine & LF-IGG & Silice & 8,2 & $0,005 \mathrm{~mol}^{. \mathrm{I}^{-1}} \mathrm{PO}_{4}{ }^{2-}$ & $\begin{array}{l}0,5 \mathrm{~mol} . \mathrm{I}^{-1} \mathrm{HAC} \\
0,1 \mathrm{~mol} . \mathrm{I}^{-1} \mathrm{NaCl}\end{array}$ \\
\hline Entremont & $\begin{array}{l}\text { LF-LP } \\
\text { IGG }\end{array}$ & $\begin{array}{l}\text { Silice } \\
\text { Spherosil }\end{array}$ & 6,4 & $0,15 \mathrm{~mol} .1^{-1} \mathrm{NaCl}$ & Acide $\mathrm{pH}$ 1-4 \\
\hline Snow Brand & LF & $\begin{array}{l}\text { Cellulofine } \\
\text { Cellulose- } \mathrm{H}_{2} \mathrm{SO}_{4} \\
\text { Chitine- } \mathrm{H}_{2} \mathrm{SO}_{4}\end{array}$ & 5 & $\begin{array}{l}0,3 \text { mol. } .^{-1} \mathrm{NaCl} \\
0,3 \mathrm{~mol}^{-I^{-1}} \mathrm{Na}_{2} \mathrm{HPO}_{4}\end{array}$ & $\begin{array}{l}1 \mathrm{~mol}^{-1} \mathrm{I}^{-1} \mathrm{NaCl} \\
1 \mathrm{~mol}^{-1} \mathrm{NaCl}\end{array}$ \\
\hline SMR & LF-LP & S-Sepharose & 6,5 & $0,01 \mathrm{~mol}^{\mathrm{I}^{-1}} \mathrm{PO}_{4}{ }^{2-}$ & $\begin{array}{l}0,075 \mathrm{~mol} .1^{-1} \mathrm{NaCl} \\
0,3 \mathrm{~mol} .1^{-1} \mathrm{NaCl} \\
0,9 \mathrm{~mol}^{-1} \mathrm{I}^{-1} \mathrm{NaCl}\end{array}$ \\
\hline Morinaga & LF & Carboxyméthyl & 6,7 & 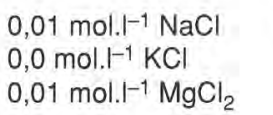 & $1,5 \mathrm{~mol}^{-1^{-1} \mathrm{NaCl}}$ \\
\hline
\end{tabular}


et la constante d'affinité des molécules sur la résine;

- en tenant compte de la spécifité du groupement ionique, afin que seules les molécules visées s'absorbent, ne perturbant, en aucun cas, les caractéristiques physiques de la matière première.

Enfin, du point de vue économique, il faut tenir compte des possibilités de régénération des résines.

\section{Lactoferrine}

Le rôle de la lactoferrine est étroitement lié à l'importance du fer. Si le fer est un métal précieux pour la vie, il peut aussi devenir un poison. Sous forme libre, le fer en trop grande quantité présente une menace pour l'organisme. En effet, c'est un élément indispensable pour les bactéries infectieuses et les cellules tumorales. II influence également le développement de certains cancers et joue un rôle sans équivoque dans le développement de l'arthrite. $\checkmark$ Brock (1989) a mis en évidence qu'il existait une relation étroite entre ce métal à l'état libre et l'immunité. En fait, les cellules du système immunitaire protègent les tissus de la toxicité du fer, jouant ainsi un rôle primordial dans le contrôle de la concentration du métal. De telles cellules synthétisent et relarguent des protéines telles que la lactoferrine, la transferrine et la ferritine, capables de neutraliser le fer, c'est-à-dire d'éliminer sa toxicité en le fixant.

La lactoferrine est une glycoprotéine que l'on retrouve dans la plupart des sécrétions externes, lait, salive, larmes etc. et dans les leucocytes polymorphonucléaires. Son poids moléculaire est de 77000 et elle contient 2 sites qui lui permettent de fixer chacun un ion ferrique $\left(\mathrm{Fe}^{3+}\right)$. Le bicarbonate est essentiel pour la fixation du fer. Le complexe lactoferrinefer est très résistant à la protéolyse et très stable jusqu'à un $\mathrm{pH}$ aussi bas que 2. La lactoferrine native possède un taux de saturation en fer de 10-30\%. La présence de citrate peut déplacer le bicarbonate de la lactoferrine et, dès lors, relarguer le fer. Toutefois, la fixation du fer dépend du rapport bicarbonate/citrate, influençant ainsi l'activité bactériostatique de la lactoferrine.

L'attention des chercheurs fut d'abord attirée par l'activité antibactérienne de la lactoferrine. Cet intérêt très vif fut lié au fait qu'il était évident que les enfants nourris au sein, étaient moins susceptibles aux infections microbiennes que les enfants nourris au biberon. Malheureusement, l'activité antibactérienne bien authentique in vitro, n'a pas encore été prouvée de manière concluante in vivo. Actuellement, il est généralement accepté que la lactoferrine paralyse les bactéries, de haute exigence en fer (ie E coli), lorsqu'elles sont incorporées dans le lait humain. De même, la raison d'être de l'utilisation de la lactoferrine dans les formules de nourriture destinées aux enfants provient des effets du lait humain sur la flore intestinale des bébés.

Que des enfants soient nourris au sein ou au biberon, leur intestin est d'abord colonisé par des entérobactéries gram-. Leur matière fécale peut contenir de manière prédominante des $E$ coli. Cette colonisation de départ, fut observée chez beaucoup d'espèces animales, en analysant non pas la flore fécale mais le contenu bactérien dans les différentes sections de l'intestin. Ce n'est qu'après une semaine que les bébés nourris au sein, possèdent dans leur flore fécale des bifido-bactéries dépassant les entérobactéries dans la proportion de 1000 pour 1. Comme on peut l'observer figure 2, la flore des nourrissons ayant reçu un lait classique et celle de ceux qui ont reçu ce même lait mais contenant une certaine quantité de lactoferrine 
(65 mg/l) contiennent des proportions différentes des 2 lignées de germes. Morinaga a également démontré que la présence de lactoferrine dans un lait destiné à l'alimentation infantile augmente le taux d'inhibition des bactéries nuisibles et permet à la flore d'être proche de celle des enfants nourris au sein (fig 3).

Un autre fait, illustrant le phénomène décrit ci-dessus a été observé par l'étude du développement de la flore intestinale chez les nourrissons ayant reçu des formulations contenant un taux important de fer métallique (sulfate de fer) pour empêcher les anémies. II fut démontré de manière concluante que même $5 \mathrm{mg} / \mathrm{l}$ de fer (la plupart des formules en contiennent au moins $12 \mathrm{mg} / \mathrm{l})$, ont un effet sur le développement de la flore intestinale durant les 12 pre- mières semaines après la naissance. Contrairement aux enfants nourris au sein, pour lesquels les bifidobactéries dominent les $E$ coli, les enfants recevant une formule de lait fortifié en fer, possèdent un taux important de $E$ coli et d'autres entérobactéries. On a même pu observer une déstabilisation des Bifidus.

Mais la simple explication de l'effet de la lactoferrine fixant le fer du milieu, permettant ainsi l'inhibition de croissance n'est pas défendable. En effet, si la lactoferrine est capable d'inhiber la croissance des cellules de Bacillus stéarothermophilus ou de Bacillus subtilis sous leur forme végétative, d'autres composés capables de fixer le fer, tels les desferrioxamines, n'ont montré aucune activité inhibitrice. De plus, Stuart et al (1984) ont prouvé que la lactoferrine agit

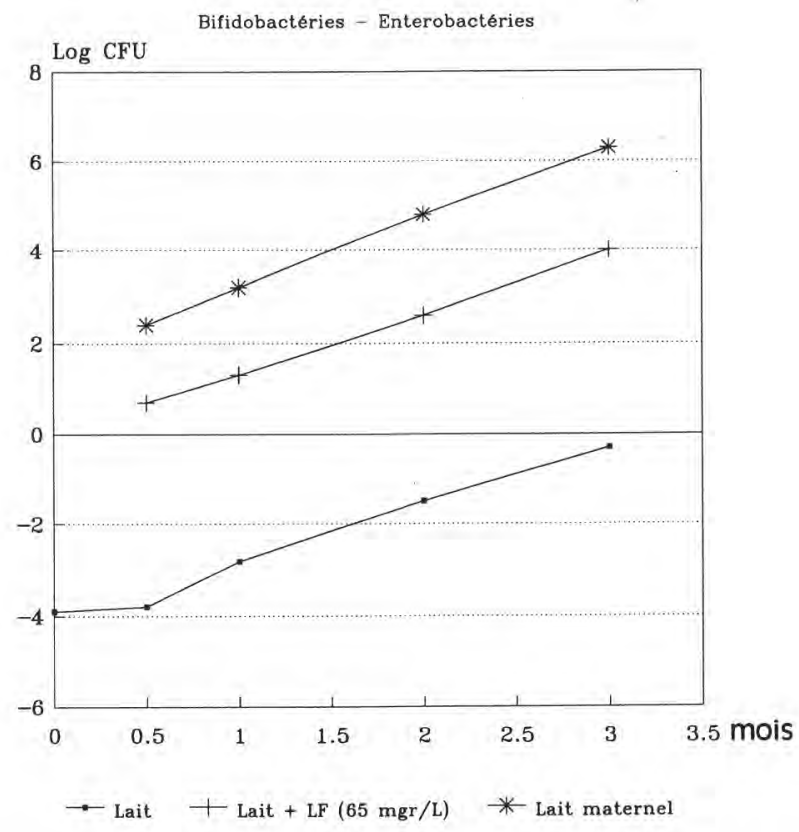

Fig 2. Bactéries contenues dans la matière fécale d'enfants nourris au lait maternel $\left(^{\star}\right)$, avec un lait contenant de la lactoferrine (+) et un lait classique (四).

Bacteria contained in the feces of babies fed with breastmilk $\left(^{*}\right)$, with milk containing lactoferrin (+)

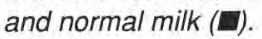




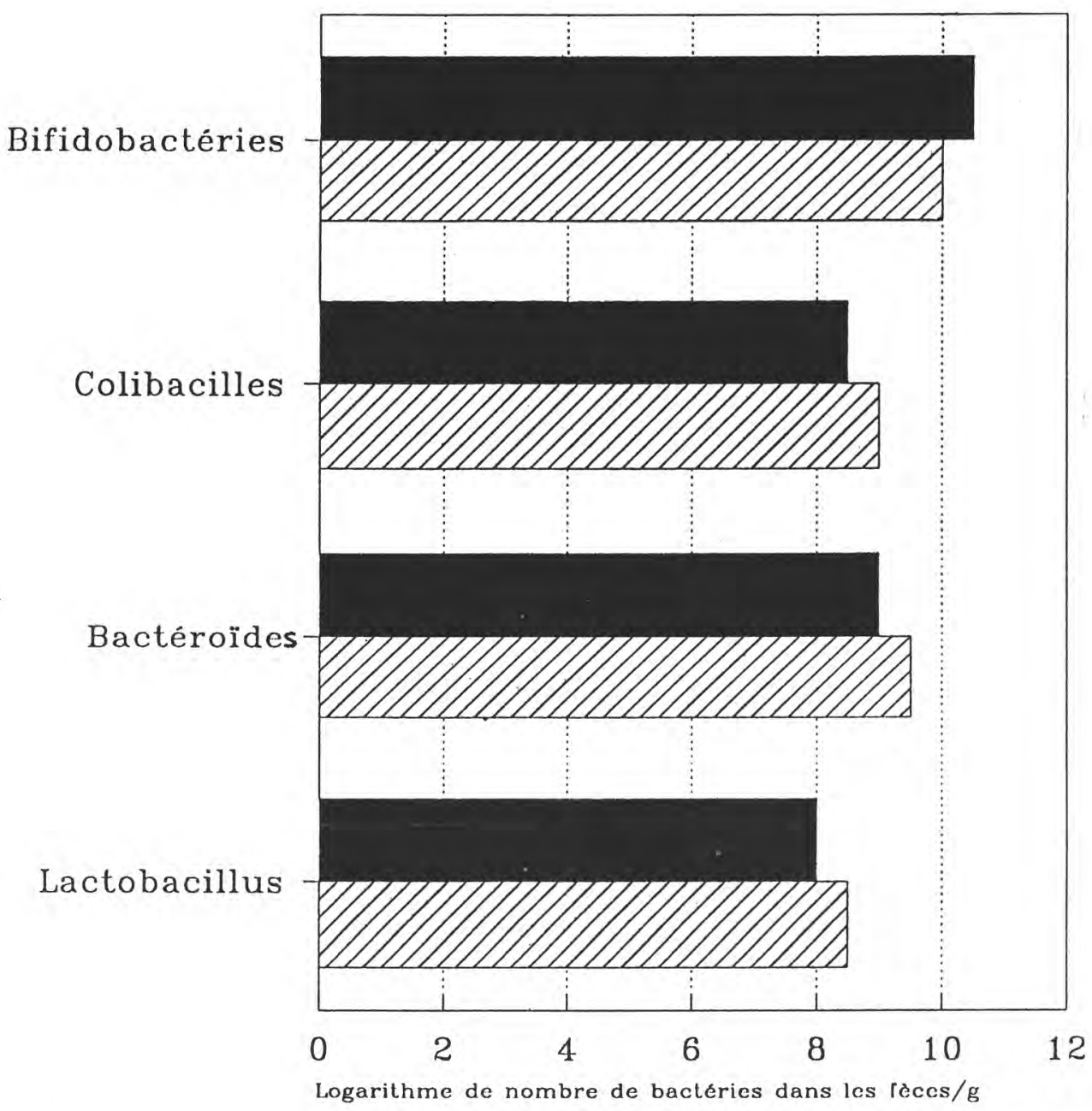

Fig 3. Bactéries contenues dans la matière fécale d'enfants nourris au lait maternel (barre noire) et d'enfants nourris avec un lait (BF-L) actuellement en vente au Japon par la société Morinaga (barre hachurée).

Bacteria contained in the feces of babies fed with breastmilk (black bar) and with milk (hatched bar) named BF-L and sold by Morinaga Company in Japan. breast milk: III milk BF-L.

directement sur les coliformes. Ils ont montré que l'ajout de lactoferrine en large excédent par rapport à la quantité de fer présent dans le milieu, augmentait l'effet inhibiteur de la croissance des $E$ coli. De leur côté, Kalfas et al (1990) et Naidu et al (1990a, b, c, d) ont démontré que l'action de la lactoferrine vis-à-vis d'un nombre important d'espèces comme le Yersinia, le Campylobacter, les Salmonelles, les shi- 
gelles, le Staphylococcus aureus, le Porphyromonas gingivalis, se faisait par une liaison spécifique entre la lactoferrine et chacun de ces microorganismes. Ils ont également réussi à isoler le récepteur de la lactoferrine se trouvant sur la membrane du Staphylococcus aureus.

Depuis lors, les chercheurs se sont penchés sur le rôle possible des sidérophores dans le mécanisme d'inhibition des microorganismes par la lactoferrine. En fait, sous des conditions de stress (c'est-à-dire avec des niveaux de fer limités), beaucoup de microorganismes synthétisent des sidérophores (protéines bactériennes fixatrices du fer) telles que l'aérobactine et l'entérocholine. Le mécanisme d'action de ces protéines secrétées par les microorganismes, consiste à fixer le fer du milieu; et à transporter le métal sur certaines protéines membranaires au niveau desquelles le fer sera internalisé. Or in vitro, il a été démontré que les sidérophores sont capables de fixer le fer avec une constante d'affinité nettement supérieure à celle de la lactoferrine et sont même capables de déplacer le fer de la lactoferrine. La question qui se pose est de savoir quelles sont les relations existantes entre la synthèse des sidérophores et la présence de la lactoferrine dans le milieu.

Les interactions entre la lactoferrine et les microorganismes ont également pu être mises en évidence lorsque l'on associe la molécule avec du lysozyme (Perraudin et Prieels, 1982). Ces expériences ont montré que lors de la libération des protoplastes du Microccoccus luteus par l'activité du lysozyme, la présence de lactoferrine permettait leur agglutination (fig 4). Ce même phénomène fut observé par Suzuki et al (1989) dans le cas de E coli, et par Soukka et al (1990) dans le cas des Streptococcus mutans.

D'un autre côté, Shimamura (1989) s'est penché sur l'effet promoteur de la lactoferrine sur les bifidobactéries (fig 5).
Le résultat final de ces 2 actions de la lactoferrine sur les microorganismes renforce les observations faites sur la flore des enfants nourris soit au sein, soit avec un lait contenant du fer, soit avec un lait contenant de la lactoferrine.

Toutefois, le rôle de la lactoferrine ne se limite pas à son action sur les microorganismes. Bien que son importance ait été controversée pendant des années, elle apparaît de plus en plus comme un constituant essentiel du lait maternel, sur le plan de la nutrition en fer. Elle joue un rôle central dans l'apport du fer aux nourrissons. Cette idée a été concrétisée par la caractérisation dans les selles des nourrissons alimentés au sein, de lactoferrine partiellement dégradée, mais encore capable de fixer le fer du milieu. Les premières expériences, suggérant une spécificité de reconnaissance de la lactoferrine et l'absence de reconnaissance des transferrines, ont été réalisées par Cox et al (1979), sur des biopsies provenant du duodénum humain. La présence d'un récepteur membranaire spécifique des lactoferrines à la surface de la bordure en brosse des entérocytes présents dans la partie duodénale a été mise en évidence par Mazurier et al (1985) sur des entérocytes de lapin, par Hu et al (1989) sur des entérocytes de souris et par Davidson et Lönnerdal (1985) sur des entérocytes de singe. Le récepteur ainsi isolé, possède une masse moléculaire de 100000 . II fixe d'une manière spécifique et saturable les différentes lactoferrines. La fixation ne dépend pas du degré de saturation en fer de la protéine, mais du $\mathrm{pH}$, avec un maximum à $\mathrm{pH} 5,5$. Elle est, en outre dépendante de la concentration en calcium. La partie glycannique de la protéine ne joue pas de rôle dans le mécanisme de reconnaissance, c'est la partie protéique des lactoferrines qui est reconnue. Le récepteur ne présente aucune affinité pour les transferrines sur la bordure en brosse et sa pré- 


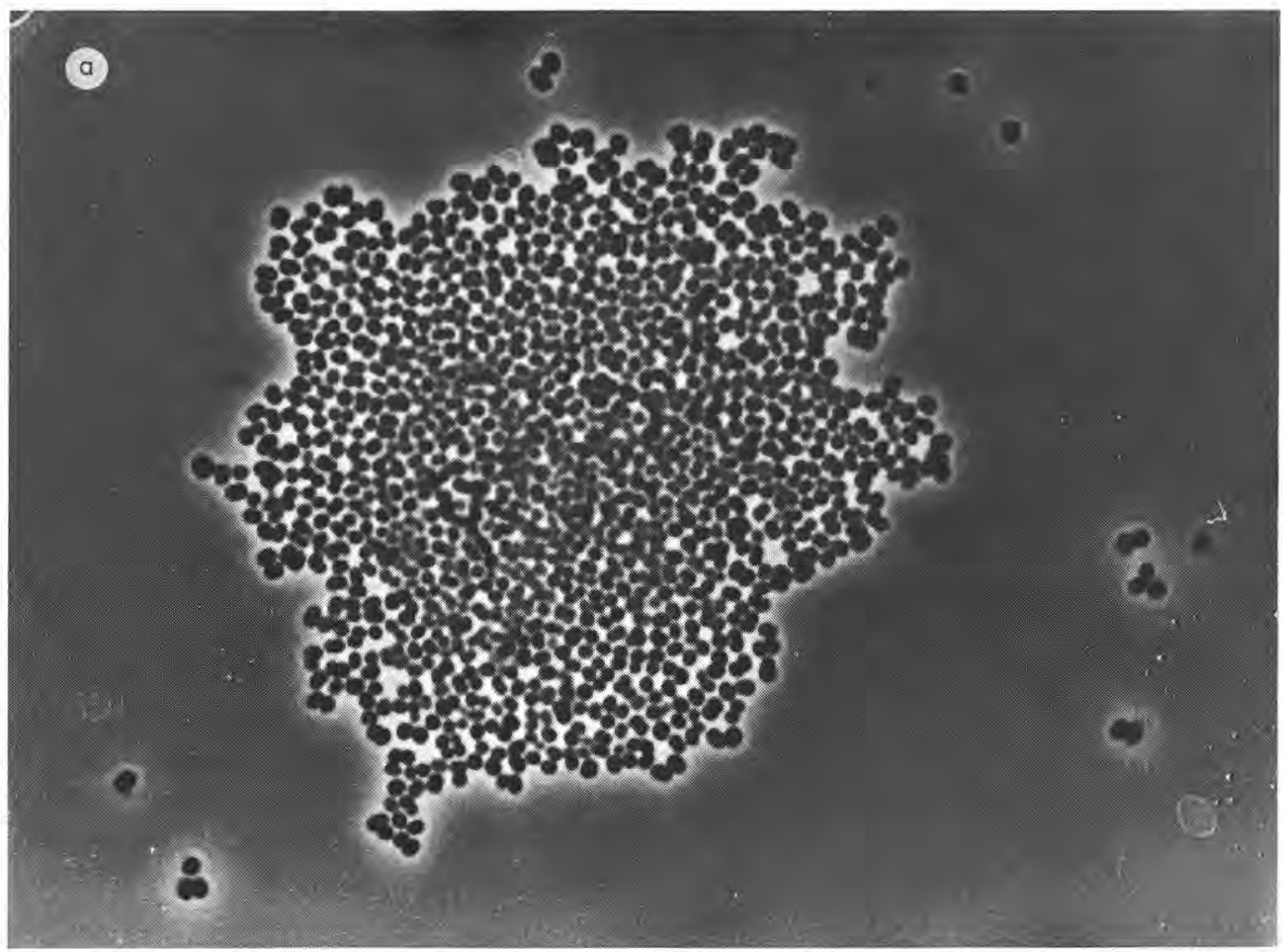

Fig 4. Photographies au microscope d'une suspension de cellules a en présence de lactoferrine humaine et $\mathbf{b}$ en absence.

Light microscopy pictures of the cell suspension in presence of human lactoferrin (a) and in its absence (b).

sence, par contre, sur les membranes basolatérales a été démontrée par microscopie électronique.

Nous savons depuis déjà un certain temps que le colostrum et les laits favorisent le développement des intestins. Widdowson (1985) et ses collaborateurs ainsi que bien d'autres chercheurs tels Berseth et al (1983), Heird et al (1984) ont établi que le colostrum et le lait donnés aux porcelets, rats, lapins et chiens accélèrent la maturation du tractus intestinal, impliquant que la structure des protéines du lait ingéré pourrait avoir une signification biologique autre que la simple fourniture d'acides aminés (tableau II). Plusieurs groupes de chercheurs ont tenté de déterminer la nature des facteurs mitogènes présents dans le lait. Récemment, Nichols et al (1987) identifièrent la lactoferrine en tant que promoteur de l'accroissement. Pour ce faire, ils analysèrent l'incorporation de thymidine marquée dans l'ADN de cellules de cryptes récoltées chez des rats adultes. Les formules basées sur le lait bovin, le soja et les hydrolysats de caséine neutralisent l'incorporation de la thymidine dans I'ADN, respectivement de 14,33 et $44 \%$. L'addition de lactoferrine au lait bovin et au lait de soja restaure partiellement l'incorpora- 


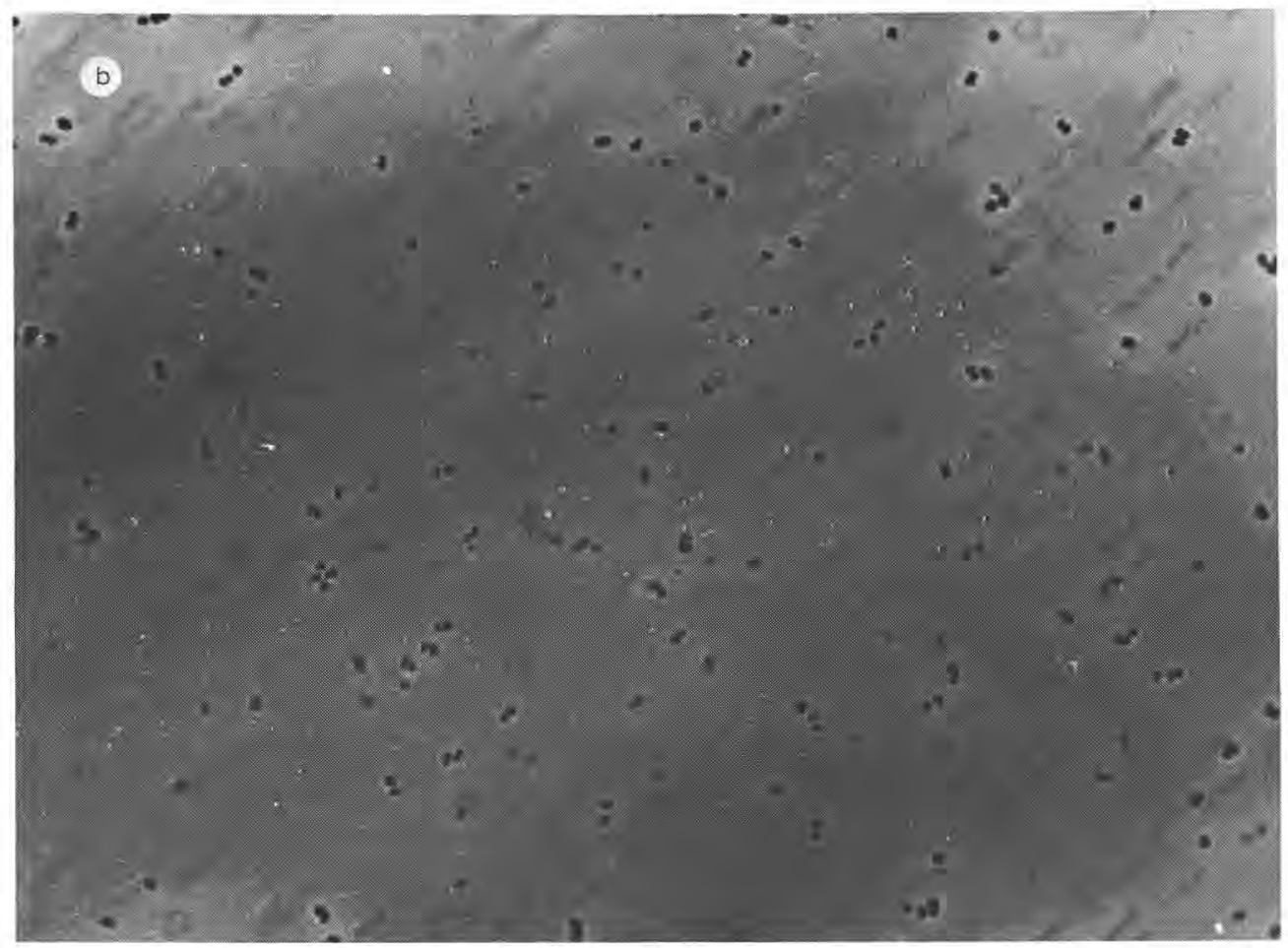

tion de la thymidine dans I'ADN, ce qui ne fut pas le cas avec les hydrolysats de caséine (tableau III). Cet effet indirect sur le développement digestif donnerait 2 nouvelles facettes à l'activité biologique de la lactoferrine.

Si la lactoferrine est nécessaire, (comme semblent le prouver les expériences de Nichols), à l'augmentation de la longueur et du poids de l'appareil intestinal, elle peut également réparer les tissus endommagés par une infection générée in vivo par la présence de fer libre.

De par l'ensemble de ces données, la lactoferrine apparaît donc comme un constituant essentiel du lait maternel, au plan de la nutrition du fer. Toutefois, son rôle ne se limite pas à ce seul aspect. En effet, la digestion et l'absorption intestinale sont liées à la bonne santé de l'intestin. À cet égard, la lactoferrine joue un rôle central dans les mécanismes de la défense infectieuse de l'intestin.

Ces différents mécanismes soulignent la diversité d'action et l'importance de la lactoferrine dans l'alimentation du nouveau-né.

\section{Le système peroxydase}

\section{Introduction}

Les peroxydases sont des enzymes (protéines) qui font partie des systèmes de défense naturels non immunitaires décrits dans le lait et les sécrétions des glandes exocrines telles la salive, les larmes, ou les sécrétions intestinales.

Moins spécifiques que les éléments du système immunitaire, ces systèmes de protection jouent un rôle de défense contre 


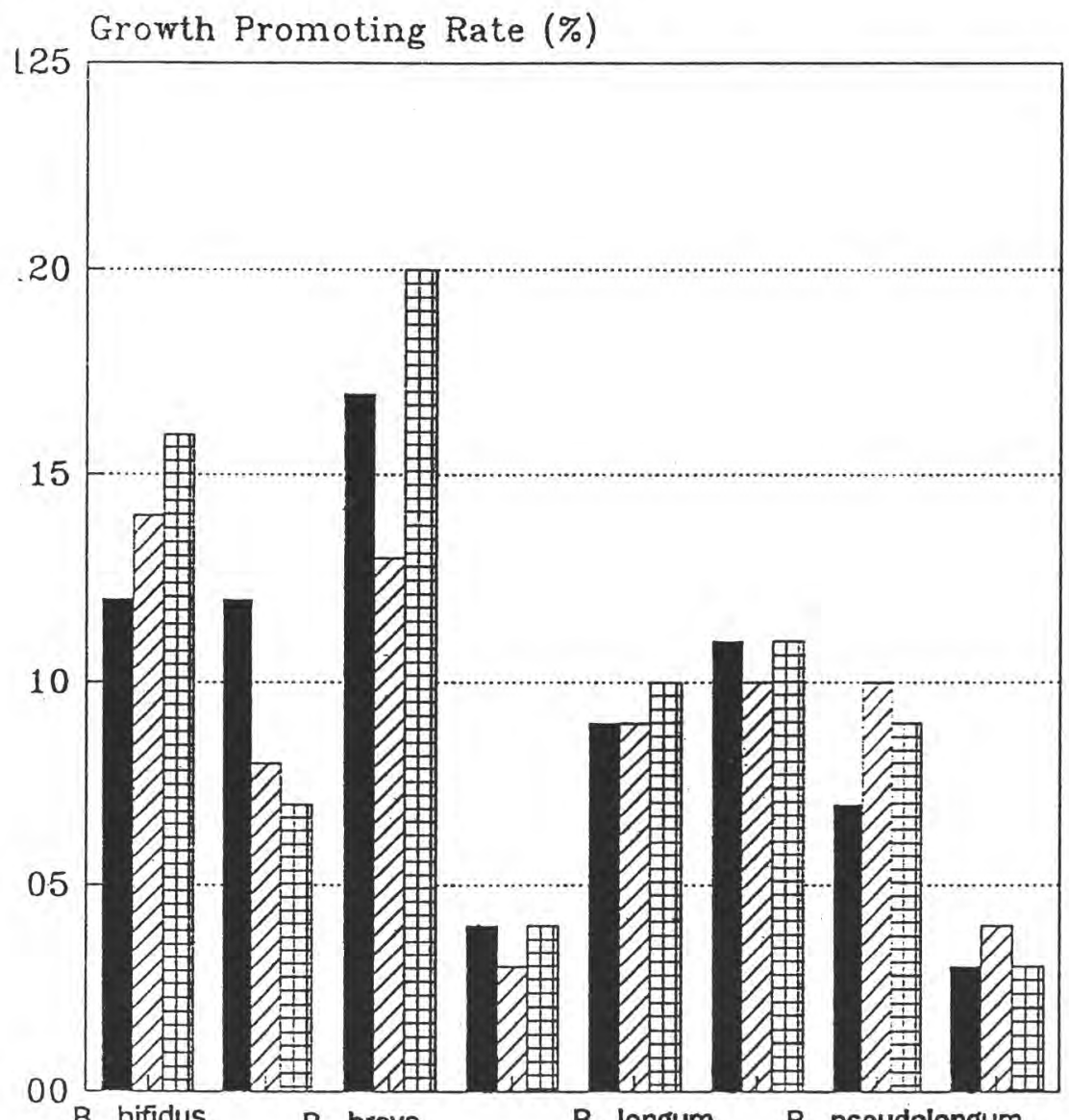

B. bifidus

B. breve

B. Iongum

B. pseudolongum

B. infantis

B. adolescentis

B. animalis

B. thermophilum

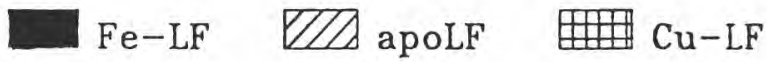

Fig 5. Effet de la lactoferrine sur la croissance de Bifidobacteries.

Effect of lactoferrin on the growth of Bifidobacterium species.

l'envahissement des muqueuses par les bactéries.

Les peroxydases n'ont pas d'activité antibactérienne par elles-mêmes, mais, mises en présence de cofacteurs déterminés, elles constituent un puissant système de défense. Ces cofacteurs sont, d'une part le peroxyde d'hydrogène $\mathrm{H}_{2} \mathrm{O}_{2}$, et d'autre part un ion, qui selon la spécificité de l'enzyme peut être l'ion thiocyanate $\mathrm{SCN}^{-}$, l'ion chlorure $\mathrm{Cl}^{-}$, l'ion bromure $\mathrm{Br}^{-}$ ou l'ion iodure I-.

Par exemple, la myéloperoxydase, présente dans les leucocytes, catalyse l'oxydation par le peroxyde d'hydrogène des ions $\mathrm{Cl}^{-}, \mathrm{Br}, \mathrm{SCN}^{-}, \mathrm{I}^{-}$; la lactoperoxydase 
Tableau II. Poids d'organes de chiens nouveaux-nés pendant les 24 premières $h$. Organ weights $(g)$ of newborn puppies during the first 24 hours.

\section{À la naissance Après avoir têté $24 \mathrm{~h} \quad$ Nourri artificiellement}

$\begin{array}{lrrr}\text { Estomac } & 1,17 \pm 0,18 & 1,57 \pm 0,15 & 1,39 \pm 0,19 \\ \text { Duodenum } & 0,89 \pm 0,17 & 1,27 \pm 0,09 & 1,11 \pm 0,02 \\ \text { Jejunum et lleum } & 6,86 \pm 1,39 & 10,20 \pm 1,20 & 7,67 \pm 0,16 \\ \text { Muqueuse } & 3,35 \pm 0,73 & 5,86 \pm 0,86 & 3,40 \pm 0,24 \\ \text { ADN de la muqueuse }(\mathrm{mg}) & 7,67 \pm 1,36 & 11,99 \pm 1,71 & 7,60 \pm 0,46\end{array}$

d'après Heird et al (1984)

du lait de vache catalyse l'oxydation des ions $\mathrm{Br}^{-}, \mathrm{SCN}^{-}$, I- et la peroxydase du raifort catalyse uniquement l'oxydation de $\mathrm{I}^{-}$.

La réaction d'oxydation catalysée par ces enzymes peut se résumer comme suit :

$$
\mathrm{H}_{2} \mathrm{O}_{2}+\mathrm{X}^{-} \rightarrow \mathrm{H}_{2} \mathrm{O}+\mathrm{OX}^{-}
$$

où $\mathrm{X}^{-}=\mathrm{SCN}^{-}, \mathrm{Cl}^{-}, \mathrm{Br}^{-}$ou $\mathrm{I}^{-}$

Le produit de la réaction, $\mathrm{OX}^{-}$, est un agent oxydant à courte durée de vie, qui va réagir, par exemple, avec les groupements $\mathrm{NH}^{2}$ ou thiols $(-\mathrm{SH})$ d'enzymes essentielles au métabolisme bactérien.

\section{Description du système lactoperoxydase du lait de vache}

C'est en 1924 que Hanssen a établi une corrélation entre l'activité bactéricide du lait cru contre Bacillus thyphosa et Bacillus parathyphosa et l'activité des oxydases et peroxydases présentes dans ce lait.

Wright et Tramer (1958), en étudiant un groupe de streptocoques, arrivèrent à la même constatation; l'inhibition a lieu dans des conditions aérobies et peut être supprimée par l'addition d'agents réducteurs
(Jones et Little, 1927; Jones et Simms, 1930). Wright et Tramer ont également suggéré que l'inhibition des germes était due à un agent oxydant formé par action de la peroxydase en présence de peroxyde d'hydrogène produit par le métabolisme des streptocoques dans des conditions d'aérobie (Wright et Tramer, 1958).

Lorsque Morrison et ses collaborateurs publièrent une méthode d'isolement et de purification de la peroxydase par chromatographie échangeuse d'ions (Morrison et al, 1957), Portmann et Auclair (1959) purent démontrer le rôle joué par l'enzyme, en rétablissant, par addition d'enzyme purifiée à du lait chauffé, une activité inhibitrice.

Jago et Morrison (1962) ont décrit le rôle joué par le peroxyde d'hydrogène; et l'observation qu'un troisième composant était nécessaire pour que fonctionne le système d'inhibition, a conduit à l'identification du thiocyanate $\mathrm{SCN}^{-}$(Reiter et al, $1964 ; 1966 b)$.

Le système lactoperoxydase est donc un système enzymatique composé de l'enzyme (lactoperoxydase) et de ses 2 substrats (le peroxyde d'hydrogène et l'anion thiocyanate) dont le produit de réaction l'anion hypothiocyanite est bactéricide à 
des concentrations de l'ordre de quelques $\mu \mathrm{mol} / \mathrm{l}$.

\section{Sources de thiocyanate et de peroxyde d'hydrogène}

\section{Thiocyanate}

L'acide thiocyanique existe sous 2 formes mésomères $\mathrm{H}-\mathrm{S}-\mathrm{C}-\mathrm{N}$ et $\mathrm{H}-\mathrm{S}=\mathrm{C}=\mathrm{N}$, en équilibre l'une avec l'autre. Ces 2 formes déprotonées sont appelées thiocyanate et isothiocyanate (Hughes, 1979).

L'anion thiocyanate est ubiquiste des tissus et sécrétions chez les mammifères. $\mathrm{La}$ concentration en $\mathrm{SCN}^{-}$dans l'organisme est fonction des habitudes alimentaires. Beaucoup de plantes sont en effet riches en glucosinolates qui, après hydrolyse, libèrent l'anion $\mathrm{SCN}^{-}$. Les légumes appartenant au genre Brassica, famille des Crucifères (chou, chou frisé, chou de Bruxelles, chou-fleur, navet, rutabaga) sont particulièrement riches en glucosino- lates. Les glucosides constituent le deuxième groupe majeur des précurseurs du thiocyanate.

Présence du thiocyanate chez l'homme et chez l'animal

Concentrations dans l'organisme humain. $\mathrm{L}^{\prime}$ ion $\mathrm{SCN}^{-}$est largement répandu dans les tissus et les sécrétions. II est présent dans la glande mammaire, la glande salivaire, la thyroïde, dans l'estomac, le rein et les fluides biologiques (liquide synovial, céphalorachidien, lymphe, plasma).

Rappelons que les concentrations en $\mathrm{SCN}^{-}$dans l'organisme sont liées à l'alimentation et sont le plus souvent plus élevées chez les fumeurs que chez les non fumeurs, ceci est dû à un cycle de détoxification du $\mathrm{CN}^{-}$contenu dans la fumée, qui aboutit au SCN-.

Concentrations chez l'animal. Les taux de $\mathrm{SCN}^{-}$mesurés dans le sérum de différents animaux sont repris dans le tableau IV.

Tableau III. Effet de facteurs de croissance sur les cellules de cryptes.

Crypt cell bioassays of trophic factors (DNA synthesis).

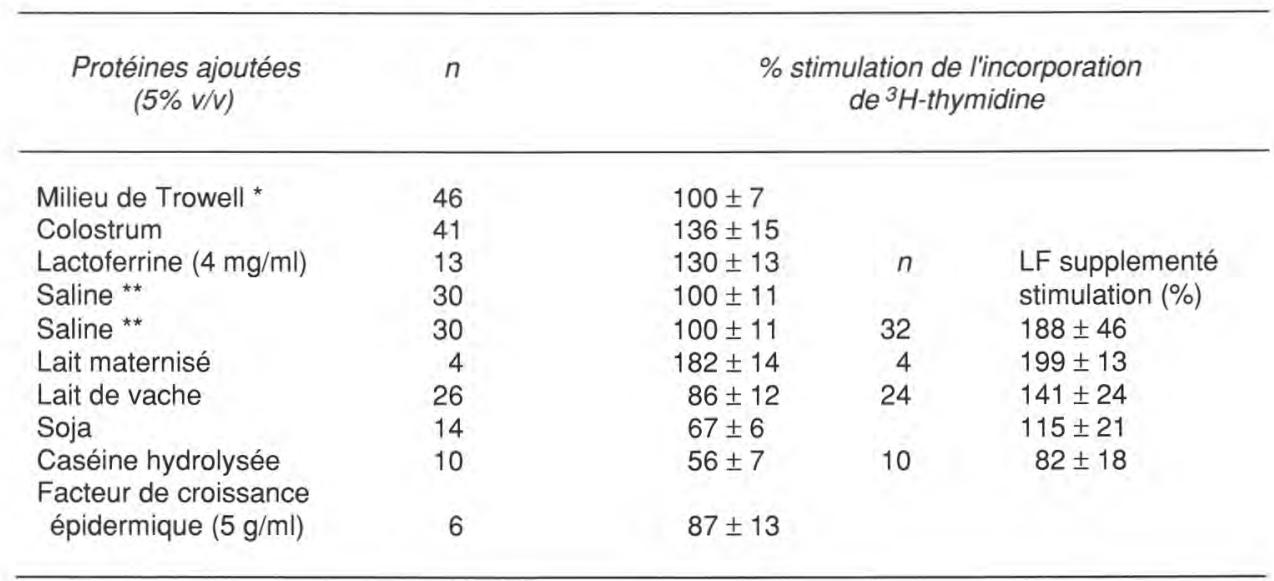

\footnotetext{
* d'après Nichols et al (1987)

** d'après Children's Nutrition Research center (1988)
} 
Les valeurs mesurées sont en général un peu supérieures à celles mesurées chez l'homme et les variations rencontrées sont attribuables aux différents types d'alimentation.

D'une espèce à l'autre, il n'existe pas de différences importantes dans la répartition du SCN- entre les organes, ainsi que dans le taux de $\mathrm{SCN}^{-}$mesuré dans les fluides biologiques. En contraste avec les valeurs élevées qui ont été mesurés dans la salive humaine, $\mathrm{SCN}^{-}$n'a pu être détecté dans la salive du cheval, du mouton, du bœuf, du porc, du cobaye et du lapin (Weuffen et al, 1982).

Concentration dans le lait de vache. Le lait de vache comprend de 0,1 à 10 ppm de $\mathrm{SCN}^{-}$, mais des concentrations supérieures ont été décrites (15 ppm). La concentration en thiocyanate dans le lait varie selon les saisons, avec une valeur minimale en hiver (janvier-février) et maximale en été; elle dépend du régime ali-

Tableau IV. Taux en $\mathrm{SCN}^{-}$sérique chez différents animaux.

Serous SCN- levels in different animals.

\begin{tabular}{lc}
\hline \multicolumn{1}{c}{ Animal } & $\mathrm{mg}(\mathrm{SCN})$ )/ (sérum) \\
\hline & \\
Vache & $1,3-15$ \\
Veau d'engraissement & $3,4-8,7$ \\
Chèvre & $0,9-6,3$ \\
Mouton & $3-4,9$ \\
Porc & $0,9-4,4$ \\
Porcelet & $6-8,5$ \\
Chien & $4-10$ \\
Lapin & $0,9-10$ \\
Cobaye & $1-22$ \\
Rat & $0,3-6,7$ \\
Souris & $2-8,5$ \\
Poule & $1,4-5,3$ \\
& \\
\hline
\end{tabular}

d'après Weuffen et al (1982). mentaire de l'animal, de la consommation de trèfle, par exemple, ou de crucifères; le taux de $\mathrm{SCN}^{-}$dans le lait peut atteindre 13 ppm.

Par ailleurs, il semble que le taux de $\mathrm{SCN}^{-}$dans le lait soit influencé par l'état de santé du pis. Lorsque celui-ci présente des signes apparents d'infection, le lait contient davantage de $\mathrm{SCN}^{-}$. II contient alors plus de $5.10^{5}$ leucocytes par $\mathrm{ml}$. II semblerait donc que l'accroissement en $\mathrm{SCN}^{-}$provienne du plasma.

Dans une étude portant sur l'observationt pendant 5 années consécutives de la fluctuation saisonnière du thiocyanate dans le lait industriel, Boulangé et al (1963) démontrent la fluctuation saisonnière du taux de thiocyanate avec un minimum hivernal et un maximum estival. L'origine alimentaire de cette fluctuation avait été démontrée précédemment (Boulangé, 1959).

Le taux de $\mathrm{SCN}^{-}$dans le lait est inférieur à celui du sérum, qui lui-même est inférieur à celui de l'urine; le passage des ions $\mathrm{SCN}^{-}$du fourrage dans le lait dépendra donc du taux de $\mathrm{SCN}^{-}$dans le sérum (Virtanen et Gmelin, 1960) et des vitesses respectives d'élimination du $\mathrm{SCN}^{-}$vers la glande mammaire ou par filtration rénale.

Dans le colostrum des truies, des valeurs de 4-8 mg de SCN-II ont été décrites (Weuffen et al, 1982). Mais c'est le lait de chèvre qui semble être le plus riche en $\mathrm{SCN}^{-}$(Bernard, 1957). II en contiendrait 4 fois plus que le lait de vache.

\section{Peroxyde d'hydrogène}

La production de l'ion hypothiocyanite par le système lactoperoxydase dépendra des quantités de thiocyanate et de peroxyde d'hydrogène disponibles.

Le peroxyde d'hydrogène dans le lait peut être naturellement produit sous l'action d'oxydases, par les leucocytes poly- 
Tableau V. Concentration en $\mathrm{SCN}^{-}(\mathrm{mg} / \mathrm{kg})$ dans les tissus et les organes. $\mathrm{SCN}^{-}$concentration in tissues and organs.

\section{Origine Cheval Mouton Porc Bœuf}

\begin{tabular}{lrrrr} 
Cerveau & 0,1 & 1,2 & 0,6 & 0,6 \\
Capsules surrénales & 0,2 & 1,7 & 1,2 & 0,8 \\
Pancréas & 0,5 & 1,5 & 1,7 & 0,6 \\
Reins & 0,7 & 2,2 & 1,2 & 3,4 \\
Rate & 0,7 & 2,9 & 0,4 & 1,5 \\
Thyroïde & 0,8 & 1,1 & 1,2 & 4,3 \\
Estomac & 0,8 & 19,0 & 0,7 & 3,8 \\
Poumon & 1,1 & 1,4 & 0,3 & 1,5 \\
Foie & 1,3 & 2,7 & 0,5 & 1,3 \\
Muscle cardiaque & 1,3 & 1,8 & 0,4 & 0,7 \\
& & & & \\
\hline
\end{tabular}

D'après Weuffen et al (1982).

morphonucléaires et par le métabolisme de certains microorganismes catalase (-) (bactéries lactiques) dans des conditions d'aérobie. Cependant, le peroxyde d'hydrogène ainsi formé semble être rapidement réduit par la catalase ou la peroxydase. Si l'on inhibe ces 2 enzymes par addition de $\mathrm{NaN}_{3}$ (azoture de sodium), il est alors possible de détecter des concentrations nanomolaires de peroxyde d'hydrogène.

S'il est facile d'ajouter le peroxyde d'hydrogène dilué dans un milieu tel que le lait, comme recommandé par la FIL (1986) pour la préservation du lait dans certaines conditions climatologiques ou technologiques, il est moins évident d'assurer la libération de peroxyde d'hydrogène lors de la dissolution d'une formulation solide. Ceci est d'autant plus difficile que le peroxyde d'hydrogène, s'il est substrat de la lactoperoxydase, est également un agent chimique capable d'inactiver les enzymes par oxydation d'acides aminés tels que : les résidus tryptophane, tyrosine, méthionine, histidine, cystéine (Neumann, 1967).
II est donc primordial de parvenir à libérer le peroxyde d'hydrogène tout en le maintenant à un seuil de concentration tel que l'enzyme puisse produire l'hypothiocyanite en quantités suffisantes sans risque de dénaturations.

Le peroxyde d'hydrogène peut se conserver sous forme solide de différentes façons: soit sous forme de peroxyde d'urée, soit sous forme de peroxydes métalliques tels que les peroxydes de sodium, magnésium et calcium.

L'activation de la lactoperoxydase au moyen de ces substances est d'ailleurs préconisée par Ewos (Björck et al, 1979). Malheureusement, ces peroxydes métalliques, même conservés solides sous atmosphère inerte, libèrent le peroxyde d'hydrogène et inactivent l'enzyme.

Une alternative à l'utilisation de peroxydes métalliques, comme producteur de peroxyde d'hydrogène consiste en l'utilisation d'un système enzymatique du type glucose oxydase/glucose. La glucose oxydase catalyse la réaction suivante :

$$
\begin{aligned}
\mathrm{H}_{2} \mathrm{O}+\text { Glucose } & +\mathrm{O}_{2} \rightarrow \text { Ac Gluconique } \\
& +\mathrm{H}_{2} \mathrm{O}_{2}
\end{aligned}
$$

La quantité de peroxyde d'hydrogène produite par le système enzymatique dépendra de la concentration des 2 substrats et de l'activité spécifique de la glucose oxydase.

\section{Oxydation du thiocyanate par la lactoperoxydase}

Reiter et ses collaborateurs (1964) ont montré que dans le lait de vache, l'oxydation du thiocyanate était impliquée dans le mécanisme d'action antibactérien catalysé par la lactoperoxydase. Björck et al (1975) ont montré que l'agent actif était dialysable, c'est-à-dire une molécule de petit poids moléculaire, et que l'enzyme ellemême ne devait pas être en contact direct avec la bactérie exposée. Aune et Thomas 
(1977) d'une part, et Hoogendoorn et al (1977) d'autre part, sont arrivés à la même conclusion, que OSCN- était l'agent antibactérien du système.

\section{Activité antimicrobienne de la lactoperoxydase}

L'hypothiocyanite, OSCN-', produit d'oxydation du $\mathrm{SCN}^{-}$, réagit principalement avec les groupements thiols $(-\mathrm{SH})$ et avec les formes réduites des nucléotides de la nicotinamide (NADH et NADPH). Ces derniers sont oxydés en NAD+ et NADP+. Les groupes $-\mathrm{SH}$ appartiennent aux résidus cystéine des protéines, à la cystéine libre ou au glutathion réduit. Ils vont être oxydés en liens disulfures ( $-\mathrm{S}-\mathrm{S}-$ ), en sulfényl thiocyanates (-S-SCN) et en acides sulféniques (-S-OH) (Aune et Thomas, 1978). Le système lactoperoxydase tue ou inhibe la croissance de nombreuses espèces de microorganismes. La lactoperoxydase est catalytiquement active à des concentrations aussi faibles que $0,5 \mu \mathrm{g} / 1$ (Pruitt et al, 1979). L'activité du système peroxydase a été abondamment rapportée, contre des virus (Belding et al, 1970), des mycoplasmes (Reiter et al, 1981), des bactéries (gram- $^{-}$et gram+), des champignons (Hamon et Klebanoff, 1973), des parasites (Nogueria et al, 1982).

L'hypothiocyanite endommage la membrane cytoplasmique, ainsi que l'ont montré Marshall et Reiter en 1980 chez E coli. En effet, 10 min après que les cellules d'E coli aient été mises au contact d'une solution contenant $\mathrm{OSCN}^{-}$, un relargage d'acides aminés et de potassium se produit.

L'altération de la membrane de $E$ coli est également suggérée par un accroissement de perméabilité pour l'ion $\mathrm{H}^{+}$des cellules traitées par le système lactoperoxydase.

Il semble que la paroi cellulaire des

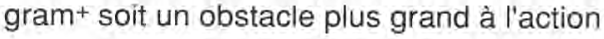

de l'hypothiocyanite que ne l'est la paroi cellulaire des bactéries gram-. II y a néanmoins des observations qui montrent l'inhibition du transport des acides aminés chez Lactobacillus acidophilus (Clem et Klebanoff, 1966; Slowey et al, 1968) et Staphylococcus aureus (Hamon et Klebanoff, 1973), le transport du glucose chez Streptococcus agalactiae (Mickelson, 1977), la prise d'oxygène et de glucose chez de nombreuses espèces. L'action in vitro du système lactoperoxydase sur une série de souches bactériennes pathogènes a également été étudiée par Van Landuydt et Lambert (1985).

D'un autre côté, le système lactoperoxydase fut testé sur des veaux (Prieels et al, 1989) à titre préventif et curatif. Le modèle in vivo consistait à traiter les veaux avec la souche $E$ coli 510 . Les résultats décrits dans la figure 6 , montrent que pour une concentration précise de lactoperoxydase, il était possible de prévenir le déclenchement de la diarrhée et de maintenir le veau sous alimentation lactée malgré une infection sévère par les colibacilles entérogènes. De même, après apparition de la diarrhée provoquée par les E coli, la lactoperoxydase est capable de faire régresser ce symptôme dans les $24 \mathrm{~h}$ et de freiner la pullulation des $E$ coli dans l'intestin, sans pour cela changer le régime alimentaire.

Cette expérience a également permis aux auteurs de constater que la présence des souches dans les matières fécales, ne montre pas de différence nette entre les veaux traités et non traités. On peut penser qu'en inhibant les synthèses protéiques, le système lactoperoxydase affecte l'attachement des colibacilles aux villosités des entérocytes de l'intestin (fig 7).

Dans le cadre d'un congrès sur la prévention alimentaire, Oléofina (Perraudin, 1990) a présenté une série de résultats concernant l'action du système lactoperoxydase dans des aliments contaminés 
score de la diarrhée

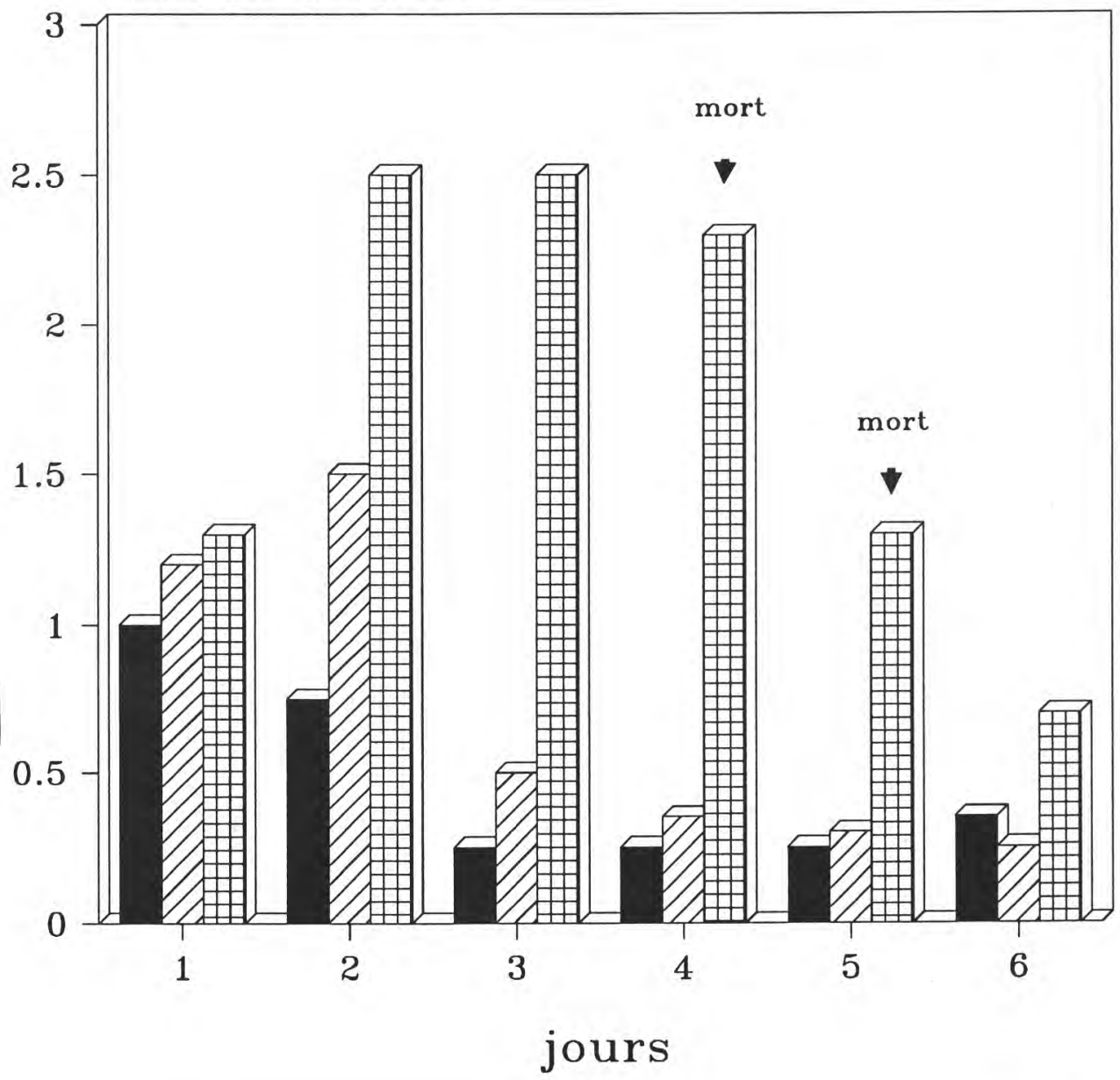

\section{LPS préventif $\square 7$ LPS curatif \# témoin}

Fig 6. Comparaison de la sévérité d'une diarrhée en fonction du type de traitement. Comparison of the severity of the diarrhoea according to type of treatment.

par différents microorganismes. Parmi ces expériences, citons celles effectuées sur le cottage cheese où le système lactoperoxydase a montré son efficacité dans la régression de la contamination dûe aux
Pseudomonas, aux Coli et aux Salmonella typhimurium. II en fut de même pour un lait maternisé contaminé par des Salmonella typhimurium. L'action du système s'est révélée également très efficace dans les 


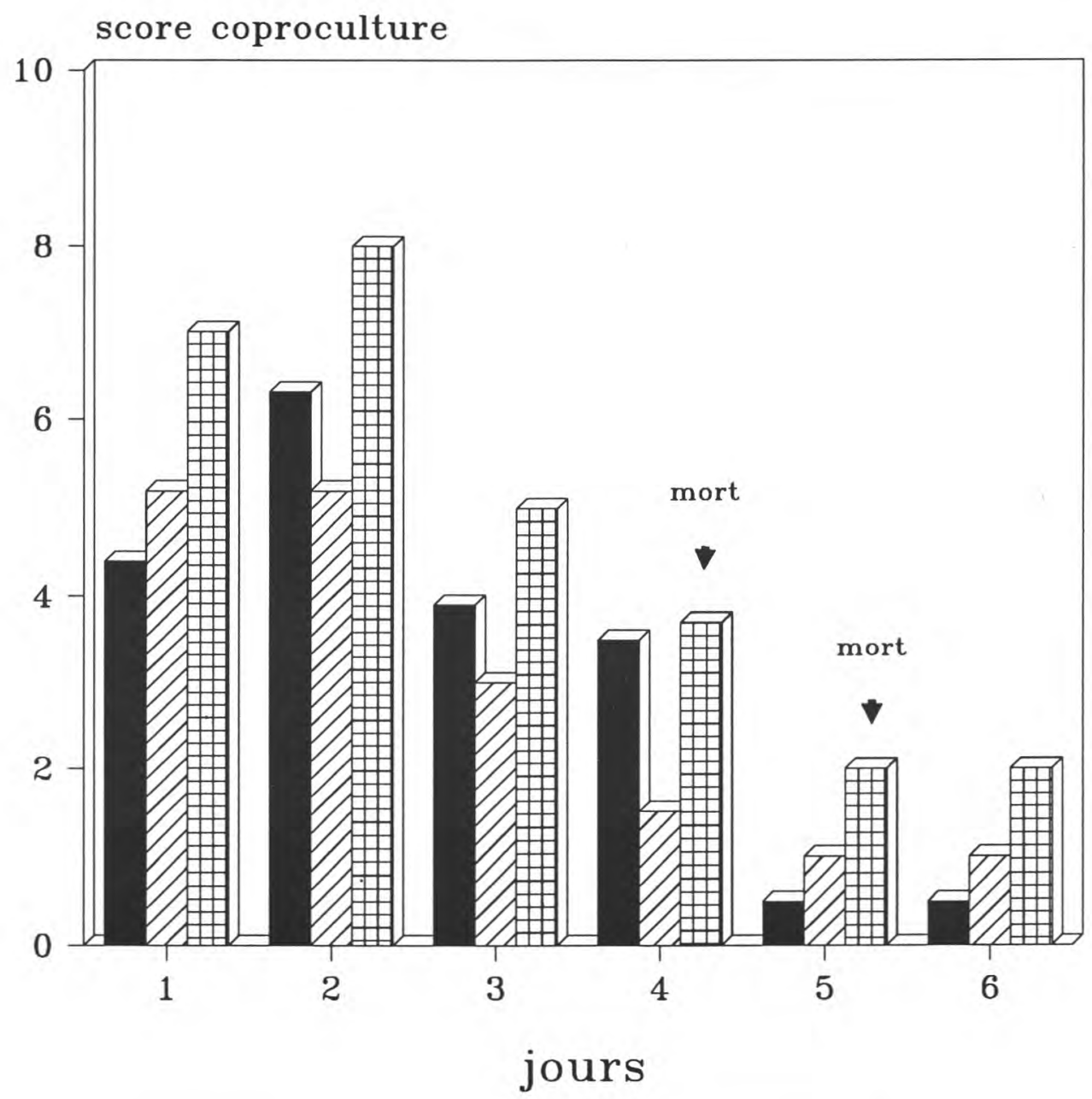

\section{LPS préventif $\square Z \triangle$ LPS curatif \#丑 contrôle}

Fig 7. Concentration des ETEC, dans les selles, en fonction du traitement.

Comparison of the excretion of ETEC organisms in the stools according to treatment.

crèmes glacées et la crème pâtissière permettant ainsi d'augmenter le temps de conservation de ces 2 aliments.

Par ailleurs, une série d'expériences conduites par Courtois et al (1990) a pu démontrer l'action du système lactoperoxydase contre des microorganismes anaérobies responsables chez les patients de parodontite chronique évolutive. Dans ce domaine, la même équipe a mené une 
étude prouvant que l'ion hypothiocyanite était capable d'abolir l'effet cytopathique du virus de l'herpès (fig 8). Ne s'arrêtant pas là, ils ont conduit plusieurs expériences arrivant à la conclusion que l'ion hypothiocyanite était capable d'inhiber complètement le virus responsable de l'immuno-déficience chez l'homme.

Ces expériences tendent à confirmer que le système peroxydase est un puissant système naturel de défense. Cette activité a été exploitée avec succès dans plusieurs applications.
C'est ainsi que l'activation de la lactoperoxydase du lait cru a permis de préserver la qualité bactériologique du lait non réfrigéré dans les pays tropicaux. De même, l'activation de la peroxydase de la salive a permis d'observer chez des sujets traités une réduction de l'apparition de caries, de parodontites et de la formation de la plaque dentaire.

Enfin, il semble que le système peroxydase puisse jouer chez le jeune ruminant un rôle actif dans la régulation de la flore intestinale. Par ses propriétés bactériosta-

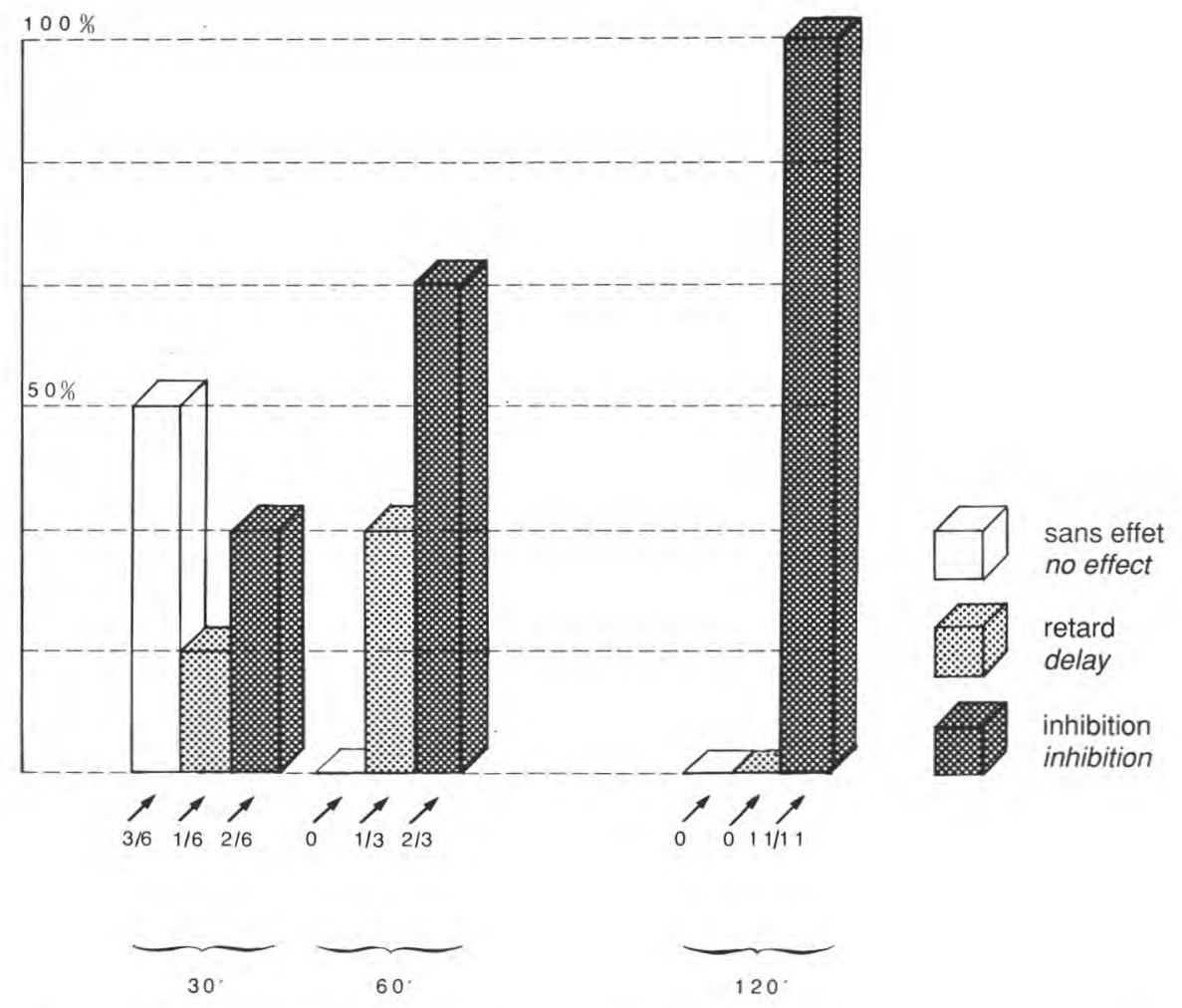

Fig 8. Diagrammes représentant les résultats obtenus après $30,60,120$ min de prétraitement du HVS1 (Herpes Simplex Virus) par le système lactoperoxydase.

Diagrammatic representation of the results obtained after 30,60 and 120 min pre-treatment of HSV1 (Herpes simplex virus) with the lactoperoxidase system. 
tiques et bactéricides, le système lactoperoxydase pourrait en effet favoriser la colonisation du jéjunum-duodénum par la flore lactique au détriment des pathogènes tels que E coli, Salmonelles ou Campylobacter.

\section{RÉFÉRENCES}

Aune TM, Thomas EL (1977) Accumulation of hypothiocyanite ion during peroxidase catalysed oxidation of thiocyanate ion. Eur J Biochem 80, 209-214

Aune TM, Thomas EL (1978) Oxidation of protein sulfhydryls by products of peroxidasecatalyzed oxidation of thiocyanate ion. Biochemistry 17, 1005-1010

Belding ME, Klebanoff SJ, Ray GC (1970) Peroxidase-mediated virucidal systems. Science $167,195-196$

Bernard C (1957) Leçons sur les effets des substances toxiques et médicamenteuses, $395 \mathrm{p}$

Berseth CL, Lichtenberger LM, Mourriss FH (1983) Comparison of the gastrointestinal growth-promoting effect of rat colostrum and mature milk in newborn rats. Am J Clin Nutr $37,52-60$

Björck L, Rosen G, Marshall V, Reiter B (1975) Antibacterial other Gram-negative bacteria. Appl Microbiol 30, 199-204

Björck L, Claesson O, Schultness W (1979) The lactoperoxidase/thiocyanate/hydrogen peroxide system as a temporary preservative for raw milk in developing countries. Milchwissenschaft 34, 726-729

Boulangé M (1959) Fluctuation saisonnière du taux des thiocyanates dans le lait frais de vache. CR Soc Biol 153, 2019-2021

Boulangé M, Hank K, Vert P (1963) Fluctuation saisonnière du taux des thiocyanates dans le lait frais de vache. CR Soc Biol 157, 10741076

Brock JH (1989) Iron and cells of the immune system. In: Iron and Immunity. Cancer and Inflammation (De Souza M, Brock $\mathrm{JH}$, eds) John Wiley and Sons Ltd, 81-98

Children's Nutrition Research Center (1988) Houston, Annu Rep
Clem WH, Klebanoff J (1966) Inhibitory effect of saliva on glutamic acid accumulation by Lactobacillus acidophilus and the role of the lactoperoxidase-thiocyanate system. J Bacteriol 91, 1848-1852

Courtois P, Van Beers D, de Foor M, Mandelbaum M, Pourtois M (1990) Abolition of Herpes simplex cytopathic effect after treatment with peroxidase generated hypothiocyanite. J Biol Buccale 18, 71-74

Cox T, Mazurier J, Spik G, Montreuil J, Peters R (1979) Iron binding proteins and influx of iron across the duodenal brush border. Biochim Biophys Acta 558, 120-128

Davidson LA, Lönnerdal B (1985) Isolation and characterization of monkey milk lactoferrin and identification of the specific brush border receptor. In: Proteins of Iron Storage and Transport (Spik G, Montreuil J, Crichton R, Mazurier J, eds) Elsevier, Amsterdam, 275278

Entremont (1988) Procédé pour extraire des protéines du lactosérum par adsorption et élution. Brevet Fr 8703517

FIL (1986) Commission du Codex Alimentarius, programme mixte $\mathrm{FAO} / \mathrm{OMS}$ sur les normes alimentaires $X X l^{e}$ session du comité d'experts gouvernementaux sur le code de principes concernant le lait et les produits laitiers. Rome, 2-6 juin

Hamon CB, Klebanoff SJ (1973) A peroxidase mediated, Streptococcus mitis-dependent antimicrobial system in saliva. $J$ Exp Med 137, 438-450

Hanssen FS (1924) The bactericidal property of milk. Br J Exp Pathol 5, 271-280

Heird WC, Schwarz SM, Hansen IH (1984) Colostrum-induced enteric mucosal growth in beagle puppies. Pediatr Res 18, 512-515

Hoogendoorn H, Prissens JP, Scholtes W, Stoddard LA (1977) Hypothiocyanite ion: the inhibition formed by the system lactoperoxidasethiocyanate-hydrogen peroxide. Caries Res $11,77-84$

Hu WL, Mazurier J, Sawatzki G, Montreuil J, Spik G (1988) Lactotransferrin receptor of mouse small intestinal brushborder. Binding characteristics of membrane bound and Triton X-100 solubilized forms. Biochem J 249, 435-441 
Hughes MN (1979) Chemistry and Biochemistry of Thiocyanic Acid and its Derivatives. General Chemistry. Acad Press, New York, 1-67

Jago GR, Morrison M (1962) Antistreptococcal activity of lactoperoxidase. Proc Soc Exp Biol Med 111, 585-588

Jones FS, Little RB (1927) The bactericidal properties of cow's milk. J Exp Med 45, 319-335

Jones FS, Simms HF (1930) The bacterial growth inhibitor (lactonin) of milk. The preparation in concentrated form. $J$ Exp Med 51, 327-339

Kalfas S, Andersson M, Edwardsson S, Forsgren A, Naidu AS (1990) Human lactoferrin binding to Porphyromonas gingivalis, Prevotella intermedia and Prevotella melaninogenica. J Biol Chem (sous presse)

Marshall VME, Reiter B (1980) Comparison of the antibacterial activity of the hypothiocyanite anion towards Streptococcus lactis and Streptococcus cremoris. J Gen Microbiol 120, 513-516

Mazurier J, Montreuil J, Spik G (1985) Visualization of lactoferrin brushborder receptors by ligand-blotting. Biochem Biophys Acta 821 , 453-460

Mickelson MN (1977) Glucose transport in Streptococcus agalactiae and its inhibition by lactoperoxidase-thiocyanate-hydrogen peroxide. J Bacteriol 132, 541-548

Morinaga (1988) A process for producing bovine lactoferrin in high purity. Brevet Jpn 168 $478 / 86$

Morrison MH, Hamilton B, Stotz E (1957) The isolation and purification of lactoperoxidase by ion exchange chromatography. I Biol Chem 228, 767-776

Naidu AS, Fournier JM, Kalfas S, Watts JL, Forsgren A (1990a) Comparison between bovine lactoferrin and other protein binding to Staphylococcus aureus associated with bovine mastitis. I Med Microbiol (sous presse)

Naidu AS, Fournier JM, Watts JL, Forsgren A (1990b) Bovine lactoferrin binding to Staphylococcus aureus and its comparison with other possible factors associated in the pathogenesis of bovine mastitis. J Med Microbiol (sous presse)

Naidu AS, Miedzobrodski J, Musser JM, Rosdahl VT, Hedström SA, Forsgren A (1990c)
Human lactoferrin binding in clinical isolates of Staphylococcus aureus. I Med Microbiol (sous presse)

Naidu AS, Zoltan Tigyi MD, Naidu SS, Forsgren A (1990d) Lactoferrin binding in enteropathogenic gram-negative bacteria. J Med Microbiol (sous presse)

Neumann NP (1967) Oxidation with hydrogen peroxide. In: Methods in Enzymology. Vol XI Enzyme Structure (Hirs CHW, ed) Acad Press, New-York, 485-487

Nichols BL, McKee KS, Putman M (1987) Human lactoferrin stimulates thymidine incorporation into DNA of rat cruyt cells. Pediatr Res 21, 563-567

Nogueria NM, Klebanoff SJ, Cohn ZA, Cruzi T (1982) Sensitization to macrophage killing by eosinophil peroxidase. J Immunol 128, 17051708

Oléofina (1986) Procédé de purification de protéines du lait et ses dérivés. Brevet $\mathrm{CH} 666$ 692

Oram JD, Reiter B (1966a) The inhibition of streptococci by lactoperoxidase, thiocyanate and hydrogen peroxide. I. The effect of the inhibitor system on susceptible and resistant strains of group- $\mathrm{N}$ streptococci. Biochem $J$ $100,373-381$

Oram JD, Reiter B (1966b) II. The oxidation of thiocyanate and the nature of the inhibitory compound. Biochem J 100, 382-383

Perraudin JP, Prieels JP (1982) Lactoferrin binding to lysozyme-treated Micrococcus luteus. Biochem Biophys Acta 718, 42-48

Perraudin JP (1990) Biokonservierung. Behr's Seminare, Frankfort

Portmann A, Auclair JE (1959) Relation entre la lacténine $L_{2}$ et la lactoperoxydase. Lait 39, 147-158

Prieels JP, Delahaut P, Jacquemin E, Kaeckenbeeck A (1989) Application du système lactoperoxydase au traitement de la diarrhée colibacillaire chez les veaux. Ann Med Vet 133, 143-150

Pruitt KM, Adamson M, Arnold R (1979) Lactoperoxidase binding to streptococci. Infect Immun 25, 304-309

Reiter B, Pickering A, Oram JD (1964) An inhibitory system-lactoperoxidase-thiocyanate peroxide in raw milk. 4th Int Symp on Food microbiology, Uppsala (Sweden), 297-305 
Reiter B, Fulford RJ, Marshall VE, Yarrow N, Ducker MJ, Knutsson M (1981) An evaluation of the growth promoting effect of the lactoperoxidase system in newborn calves. Anim Prod 32, 297-306

Roussel Uclaf (1985) Procédé d'extraction de protéines du lait, produits, application du procédé et compositions pharmaceutiques. Brevet Fr 8510649

Shimamura S (1989) Activité promotrice de la lactoferrine sur la prolifération du Bifidobacterium. Congr Bifidobacterium et Santé, 8-9 juin, Paris

Slowey RR, Eidelman S, Klebanoff SJ (1968) Antibacterial activity of the purified peroxidase from human parotid saliva. J Bacteriol 96, 575-579

SMR (1988) Process for extracting pure fractions of lactoperoxidase and lactoferrin from milk serum. Brevet WO 89/04 608

Snow Brand (1988) Method for separating and purifying lactoferrin from milk by use of sulfuric ester. Brevet Jpn 8845087

Société Nationale Elf Aquitaine (1982) Process of extraction of lactoferrin and immunoglobulins of milk. Brevet Fr 8109740

Soukka T, Lumikari M, Tenuovo J (1990) Synergistic bactericidal action of human lactoferrin and lysozyme against Streptococcus mutans. $J$ Oral Pathol (sous presse)
Stuart J, Norell S, Harrington JP (1984) Kinetic effect of human lactoferrin on the growth of Escherichia coli 0111. Int J Biochem 16, 1043-1047

Suzuki T, Yamauchi K, Kawase K, Tomita M, Kiyosawa I, Okonogi S (1989) Collaborative bacteriostatic activity of bovine lactoferrin with lysozyme against Escherichia coli 0111. Agric Biol Chem 53, 1705-1706

Van Landuydt HW, Lambert AM (1985) In vitro activity of lactoperoxidase, lactoferrin and lysozyme against recent clinical isolates. Second Eur Congr Clinical Microbiology, Brighton, 3-10

Virtanen A, Gmelin R (1960) The transfer of thiocyanate from fodder to milk. Acta Chem Scand 14, 941-943

Weuffen W, Kramer A, Jülich WD, Schroeder H (1982) Vorkomen bei Mensch und Tier 123158. In: Medizinische und biologische bedeutung der thiocyanate (Rhodanide) (Weuffen W, ed) VEB Verlag Volk und Gesundheit, Berlin

Widdowson EM (1985) Development of the digestive system: comparative animal studies. Am J Clin Nutr 41, 384-390

Wright RC, Tramer J (1958) Factors influencing the activity of cheese starters. The role of milk peroxidase. J Dairy Res 25, 104-118 